\title{
Design, synthesis and pharmaco-toxicological assessment of 5-mercapto-1,2,4-triazole derivatives with antibacterial and antiproliferative activity
}

\author{
MARIUS MIOC ${ }^{1,2^{*}}$, CODRUTA SOICA $^{1 *}$, VASILE BERCEAN $^{3}$, SORIN AVRAM $^{2}$, \\ MIHAELA BALAN-PORCARASU ${ }^{4}$, DORINA CORICOVAC ${ }^{1}$, ROXANA GHIULAI ${ }^{1}$, \\ DELIA MUNTEAN ${ }^{5}$, FLORINA ANDRICA ${ }^{1}$, CRISTINA DEHELEAN ${ }^{1}$, \\ DEMETRIOS A. SPANDIDOS ${ }^{6}$, ARISTIDES M. TSATSAKIS ${ }^{7}$ and LUDOVIC KURUNCZI ${ }^{2}$ \\ ${ }^{1}$ Faculty of Pharmacy, 'Victor Babes' University of Medicine and Pharmacy, Timisoara 300041; \\ ${ }^{2}$ Department of Computational Chemistry, Institute of Chemistry Timisoara of the Romanian Academy, \\ Timisoara 300223; ${ }^{3}$ S.C. SINOFIN S.R.L., Timisoara 300544; ${ }^{4}$ Institute of Macromolecular Chemistry 'Petru Poni', \\ Iasi 700487; ${ }^{5}$ Faculty of Medicine, Victor Babes' University of Medicine and Pharmacy, Timisoara 300041, Romania; \\ ${ }^{6}$ Laboratory of Clinical Virology, Medical School, University of Crete, Heraklion 71409; ${ }^{7}$ Department of Forensic Sciences \\ and Toxicology, Medical School, University of Crete, Heraklion 71003, Greece
}

Received January 3, 2017; Accepted March 1, 2017

DOI: 10.3892/ijo.2017.3912

\begin{abstract}
The extensive biochemical research of multiple types of cancer has revealed important enzymatic signaling pathways responsible for tumor occurrence and progression, thus compelling the need for the discovery of new means with which to block these signaling cascades. The phosphoinositide 3-kinase/ protein kinase B (PI3K/AKT) pathway, which plays an important role in maintaining relevant cellular functions, exhibits various alterations in common human cancers, thus representing a suitable target in cancer treatment. Molecules bearing the 1,2,4-triazole moiety are known to possess multiple biological activities, including anticancer activity. The current study used molecular docking in the design of 5-mercapto-1,2,4-triazole derivatives with antiproliferative activity targeting the PI3K/ AKT pathway. Three structures emerged as the result of this method, which indicated for these a highly favorable accommodation within the active binding site of PI3K protein, thus acting as potential PI3K inhibitors, and hence interfering with the above-mentioned pathway. The molecules were synthesized and their chemical structure was confirmed. The antiprolif-
\end{abstract}

Correspondence to: Professor Cristina Dehelean, Faculty of Pharmacy, 'Victor Babes' University of Medicine and Pharmacy, 2 Eftimie Murgu Square, Timisoara 300041, Romania

E-mail: cadehelean@umft.ro

${ }^{*}$ Contributed equally

Key words: 1,2,4-triazole, molecular docking, antibacterial, antiproliferative, alamarBlue erative activity of these compounds was tested on 4 cancer cell lines (A375, B164A5, MDA-MB-231 and A549) and on normal human keratinocytes $(\mathrm{HaCaT})$ by in vitro alamarBlue assay. The 3 compounds revealed antitumor activity against the breast cancer cell line (MDA-MB-231) and reduced toxicity on the normal cell line. The antibacterial activity of the compounds was also tested in vitro on Gram-positive and Gram-negative bacterial strains, revealing moderate activity.

\section{Introduction}

Cancer continues to be a highly challenging pathology that claims a prominent position as cause of annual mortaliy worldwide due mainly to global aging, but also to more numerous cases in developing countries (1). Current conventional chemotherapy has various limitations (i.e., severe adverse effects and resistance to treatment) (2); thus the identification of novel effective and selective antitumor compounds is mandatory. An excellent analysis of the current challenges and future objectives in the treatment of cancer reported that the continuously growing knowledge of molecular and cellular tumor biology has revolutionized cancer treatment towards: i) the technological improvement of tumor molecular profiling; and ii) the discovery of predictive molecular targets (3).

The extensive biochemical research of multiple types of cancer has revealed important enzymatic signaling pathways responsible for tumor occurrence and progression, thus compelling the need for the discovery of new means with which to block these signaling cascades. Current approaches in the discovery of novel anticancer therapies are oriented towards finding suitable molecules that act as specific inhibitors of key enzymes which play a significant role in carcinogenesis (4). The phosphoinositide 3-kinase/protein kinase B (PI3K/AKT) pathway plays an important role in maintaining relevant 
cellular functions, such as cell proliferation, survival and cell translation $(5,6)$ and its components are frequently mutated, overexpressed or altered in common human cancers; therefore, the targeting of the PI3K/AKT pathway by novel antitumor drugs represents a promising alternative in cancer treatment $(7,8)$.

Triazoles are heterocyclic aromatic 5-membered ring compounds (9) represented by two isomers: 1,2,3-triazoles and 1,2,4-triazoles, each of them having two tautomeric forms correlated with the nitrogen atom that has a hydrogen atom bonded to it (Fig. 1).

Molecules bearing the 1,2,4-triazole moiety are known to possess multiple biological activities, including anticancer activity; the chemical modulation of the triazole ring leads to the development of highly effective compounds with improved selectivity (9). A search carried out on the WOMBAT (10) database has resulted in the identification of a large number of biologically active molecules containing the 1,2,4-triazole ring. Furthermore, recent studies have reported the significant anticancer activity of newly synthesized 5-mercapto-1,2,4-triazole derivatives against several tumor cell lines (11-13). Molecular docking has aided in the design of 1,2,4-triazole derivatives that act as methionine aminopeptidase type II (MetAp2) inhibitors, thus exhibiting antiproliferative activity through the induction of apoptosis (14). A series of 25 compounds bearing the 1,2,4-triazole moiety have been synthesized and assessed as antitumor agents through docking simulation in target protein structures (RCSB PDB ID: 1YS1, 1FM6, 1BXL) and in in vitro antitumor screening, revealing significant activity on leukemia, melanoma, lung and ovarian cancer cell lines (15). In addition, a significant number of synthesized 1,2,4-triazole derivatives has been reported with significant antibacterial activity $(16,17)$.

The aim of the current study was the design and synthesis of 5-mercapto-1,2,4-triazole derivatives with eventually predicted antiproliferative and antibacterian properties; the antitumor activity is tentatively exerted through the inhibition of PI3K protein, as established by means of molecular docking. The biological activity of the identified triazole compounds was evaluated in vitro on tumor cell lines, and on several bacterial strains, respectively.

\section{Materials and methods}

Compound library building. In the current study, we aimed to create a compound library for the purpose of their virtual screening against protein targets which have been proven to be active in various types of cancer, such as breast, lung and colon cancer. The created compound library contains 5-mercapto-1,2,4-triazole derivatives (469 molecules) that were obtained by the substitution of various radicals on the 1,2,4-triazole ring, in the fourth and fifth position (R1 and R2) and on the thiol group from the third position (Fig. 2).

The compound database was prepared using OMEGA version 2.5.1.4 (OpenEye Scientific Software, Inc., Santa Fe, NM, USA) (18) and filtered by means of OMEGA's BlockBuster filter, using default parameters. After the filtering process, 200 conformers were generated for each ligand. Before the start of conformer generation, stereoisomers were generated for compounds that possess asymmetric carbons in their structure which were subsequently treated as independent molecules.
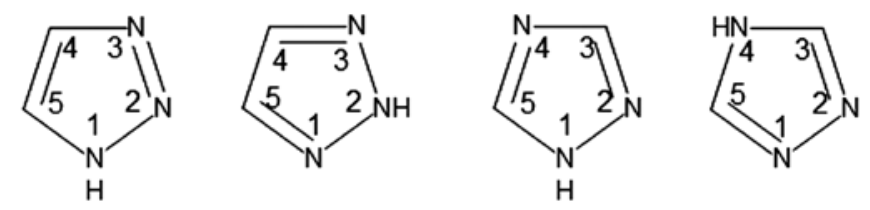

$1 H-1,2,3-T r i a z o l e$

2H-1,2,3-Triazole

1H-1,2,4-Triazole

4H-1,2,4-Triazole

Figure 1. Triazole structures.

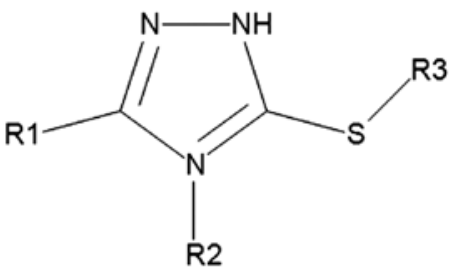

Figure 2. General structure of the molecules included in the compound library.

Molecular docking. Molecular docking was carried out using OEDocking HYBRYD version 3.0.1 (OpenEye Scientific Software, Inc.) (19), that uses the structure of a target protein and the structure of the co-crystallized ligand to dock and score molecules and also allows the selection of multiple protein targets that can be used in the docking process. Docking results interpretation was carried out using Discovery Studio 4.1 (Dassault Systemes, BIOVIA Corp., San Diego, CA, USA).

Three-dimensional crystallographic structures of the target proteins selected for this study [PI3K $\alpha$, AKT and mammalian target of rapamycin (mTOR)] were obtained from the RCSB ProteinDataBank (www.rcsb.org; accessed May, 2016) (20). A set of multiple 3D structures corresponding to each of the three protein targets, were used for docking purposes, selected by the following criteria: i) Protein structures with a co-crystallized ligand (as required by the docking software); ii) protein structures that are non-mutant; and iii) protein structures that have a Cruickshank DPI (diffraction precision index) (21) under 0.5. Protein structures were prepared as receptors, suitable for docking, using OEDocking's MakeReceptor version 3.0.1 (OpenEye Scientific Software, Inc.) (18).

The compound library was docked in each set of 3D structures corresponding to each of the three protein targets. Protein structures selected from the RCSB Protein Data Bank and used in the docking process, were the following: i) For PI3Ka protein, RCSB PDB ID's used: 4WAF, 4JPS, 4L2Y; ii) for AKT1 protein, RCSB PDB ID's used: 1H10, 1UNQ, 2UVM, 3CQU, 3CQW, 3MV5, 3MVH, 3O96, 3QKK, 3QKL, 3QKM, 4EJN, 4EKL, 4GV1; and iii) for mTOR protein, RCSB PDB ID's used: 4DRH, 4DRI, 4DRJ, 3FAP, 4FAP, 2FAP, 1NSG, 1FAP. The mechanism of the docking process employed follows four basic steps: i) A structure from the compound library is screened against the set of receptors selected for docking; ii) the molecule is docked in the protein structure which contains a co-crystalized ligand that has the best shape, chemical and topological similarities with the compound in question; iii) the docked compound is scored by the docking software; and iv) all compounds are docked and ranked according to the scoring function score (Chemgauss4) (19). 


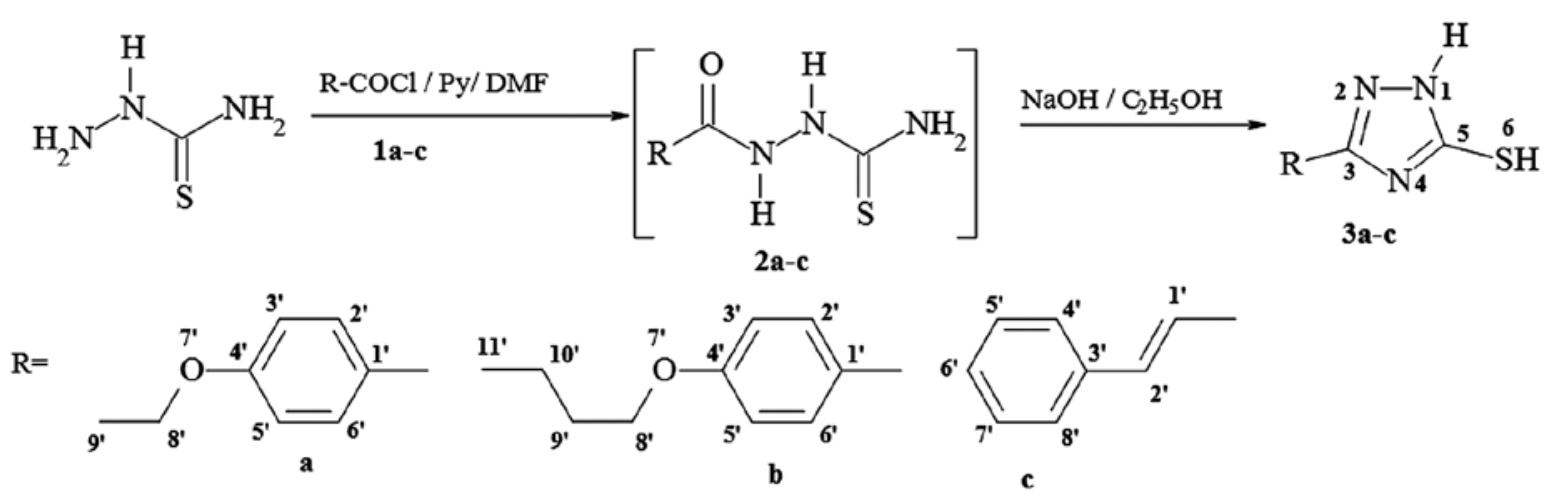

Legend

$3 \mathrm{a}=\mathrm{Tz} 53$

$\mathrm{R}-\mathrm{COCl}=$ acide chloride

$3 \mathrm{~b}=\mathrm{Tz} 55 \quad$ Py $=$ pyridine

$3 \mathrm{c}=\mathrm{Tz} 3 . \mathrm{a}$

$\mathrm{DMF}=$ dimethylformamide

Figure 3. Synthesis route of 1H-3-R-5-mercapto-1,2,4-triazoles.

Chemical synthesis. Thiosemicarbazide, 4-ethoxy-benzoic acid, 4-n-butoxi-benzoic acid, cinnamic acid, and solvents (ethanol, N,N-dimethylformamide, pyridine) were purchased [Acros Organics (Geel, Belgium); Sigma-Aldrich, (St. Louis, MO, USA)] and used as received. The acid chlorides (Fig. 3; 1a-c) were synthesized by treating the corresponding acids with thionyl chloride at reflux and used without further purification.

The synthesis of 1H-3-R-5-mercapto-1,2,4-triazoles (Fig. 3, 3a-c), was carried out by acylation of thiosemicarbazide with the corresponding acid chloride and pyridine in $\mathrm{N}, \mathrm{N}$-dimethylformamide, followed by the cyclisation reaction of the resulted 1-acyl-thiosemicarbazides (Fig. 3, 2a-c), in ethanolic $\mathrm{NaOH}$, at reflux, according to the previously published procedure (22). The synthesis route is shown in Fig. 3.

Compound characterization. Melting points were determined on a Böetius PHMK (Veb Analytik, Dresden, Germany) instrument, and thin-layer chromatography was carried out on silica gel-coated plates 60 F254 Merck using hexane: ethyl acetate (various ratios) as eluents. IR spectra were recorded in $\mathrm{KBr}$ pellet on a Jasco FT/IR-410 spectrophotometer. 1H-NMR and 13C-NMR spectra were recorded on a Bruker Avance DRX 400 spectrometer in DMSO-d6, at room temperature. The chemical shifts are reported as $\delta$ values (ppm) and were referenced to the solvent residual peak (2.51 ppm for ${ }^{1} \mathrm{H}$ and $39.47 \mathrm{ppm}$ for $\left.{ }^{13} \mathrm{C}\right)$. Elemental analysis was carried out using a Vario EL cube (Elementar Analysensysteme GmbH, Hanau, Germany). Mass spectra experiments were conducted on a 6120 Quadrupole LC/MS system from Agilent Technologies, Inc. (Santa Clara, CA USA) equipped with a UV detector, ESI ionization source and a Zorbax Rapid Resolution SB-C18 (1.8 $\mu \mathrm{m}$; 50x2.1 mm) column. LC-MS grade methanol was obtained from Merck Millipore (Darmstadt, Germany) and used without further purification. All samples were obtained by dissolving the solid samples in methanol. All samples were analyzed using methanol as the isocratic mobile phase, at a flow rate of $0.4 \mathrm{ml} / \mathrm{min}$, temperature of $25^{\circ} \mathrm{C}$ and $\lambda=250 \mathrm{~nm}$. All mass spectra were recorded in the positive ion mode under optimized ESI parameters using nitrogen nebulizer pressure at 35psi, nitrogen drying gas temperature at $250^{\circ} \mathrm{C}$ and flow rate at $12 \mathrm{l} / \mathrm{min}$ and capillary voltage of $3,000 \mathrm{~V}$ in the Scan mode.

Antibacterial assay. The three compounds were screened for their antimicrobial activity against 6 bacterial strains: Staphylococcus aureus ATCC 25923, Streptococcus pyogenes ATCC 19615, Pseudomonas aeruginosa ATCC 27853, Salmonella typhimurium ATCC 14028 and Proteus vulgaris ATCC 13315 using the agar disk-diffusion method. Culti-loops with ATCC strains were introduced into a tube with $1 \mathrm{ml}$ thioglycollate medium and these suspensions were then placed on blood agar plates and incubated $24 \mathrm{~h}$ in a $37^{\circ} \mathrm{C}$ atmosphere. All the bacterial strains were prepared from 24-h-old cultures. Bacterial suspensions were adjusted to a McFarland's standard of 0.5 (a final bacterial concentration of $1-2 \times 10^{8} \mathrm{CFU} / \mathrm{ml}$ ). The Mueller-Hinton agar plates were inoculated with bacterial suspension using a sterile cotton swab. Within 15 min following plate inoculation, sterile Whatman no. 1 filter paper disks (6 $\mathrm{mm}$ in diameter) impregnated with the test compounds $(3 \mu \mathrm{l}$ solution/disk) were distributed evenly on the plate surface leaving at least $30 \mathrm{~mm}$ (center to center) between them. DMSO and gentamycin were used as a negative and positive control, respectively. Plates inoculated with the bacterial suspensions were incubated at $37^{\circ} \mathrm{C}$ for $24 \mathrm{~h}$. The inhibition zone diameters were measured in millimeters using a ruler. For all bacterial strains duplicate disk-diffusion tests were performed and the average reading was taken into account.

Cell culture. The human tumor cell lines (A375 human melanoma cells, Cat no. ATCC ${ }^{\circledR}$ CRL-1619 ${ }^{\text {TM }}$; A549 human lung carcinoma cells, Cat no. $\mathrm{ATCC}^{\circledR} \mathrm{CCL}-185^{\mathrm{TM}}$; and MDA-MB-231 human breast carcinoma cells, Cat no. ATCC ${ }^{\circledR}$ HTB-26 ${ }^{\mathrm{TM}}$ ) were purchased from the American Type Culture Collection (ATCC, Manassas, VA, USA) via LGC Standards GmbH, Wesel Germany. The B164A5 murine melanoma cell line and cell culture media, and specific supplements were purchased from Sigma-Aldrich Co. (Ayrshire, UK). Human keratinocytes (HaCaT) were a gift from the University of Debrecen, Debrecen, Hungary. The cells were cultured in Dulbecco's modified Eagle's Medium (DMEM) containing 


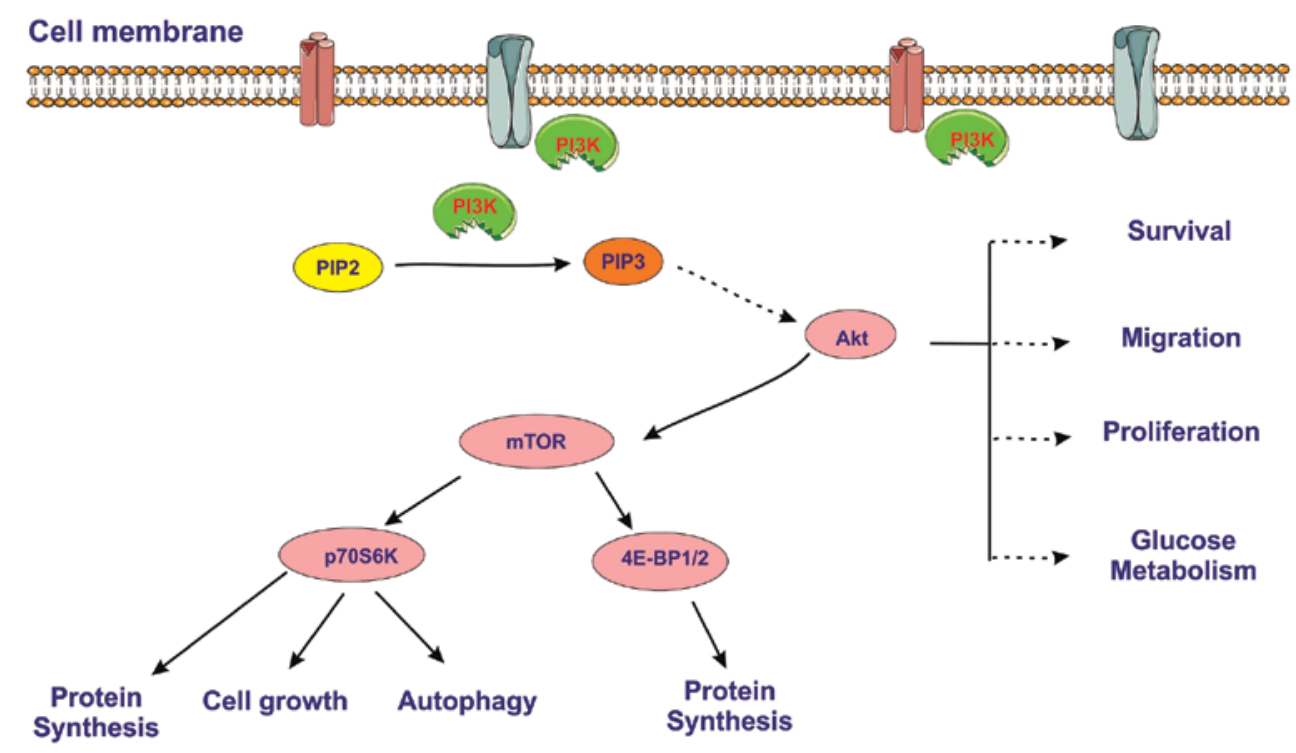

Figure 4. Simplified scheme of the PI3K/AKT/mTOR signaling pathway. PI3K, phosphoinositide 3-kinase/protein kinase B; PIP2, phosphatidylinositol 4,5-bisphosphate; PIP3, phosphatidylinositol 3,4,5-trisphosphate; Akt, serine/threonine-specific protein kinase; mTOR, mammalian target of tapamycin, a serine/threonine protein kinase; P70S6K, p70 ribosomal S6 kinase; 4E-BP1, eukaryotic translation initiation factor 4E-binding protein 1.

$4.5 \mathrm{~g} / 1$ glucose, L-glutamine and $\mathrm{NaHCO}_{3}$, and supplemented with $100 \mathrm{U} / \mathrm{ml}$ penicillin, $100 \mu \mathrm{g} / \mathrm{ml}$ streptomycin and $10 \%$ fetal bovine serum (FBS). Cells were kept under standard conditions (humidified atmosphere, $5 \% \mathrm{CO}_{2}, 37^{\circ} \mathrm{C}$ ) and passaged every second day. Cell number was determined by using the cell counting chamber (Neubauer) in the presence of Trypan blue.

alamarBlue assay (viability assay). Cell viability was measured by means of the alamarBlue technique; cells $\left(1 \times 10^{4} / 200 \mu \mathrm{l}\right.$ medium/well) were seeded in a 96-well plate, allowed to attach and then stimulated with various concentrations (10 and $50 \mu \mathrm{M})$ of the test compounds for $24 \mathrm{~h}$. At $24 \mathrm{~h}$ post-stimulation, a volume of $20 \mu \mathrm{l} /$ well of alamarBlue solution was added (10\% of the volume of cell culture medium present in each well-200 $\mu \mathrm{l})$. The plates were incubated at $37^{\circ} \mathrm{C}$ for $3 \mathrm{~h}$ and then spectrophotometrically read at 570 and $600 \mathrm{~nm}$, respectively, by using a xMark $^{\mathrm{TM}}$ Microplate Spectrophotometer (Bio-Rad, Berkeley, CA, USA). Untreated cells and pure solvent were used as control. Cell viability was calculated according to the previously published formula (23).

Scratch assay (wound healing assay). The migratory ability of various tumor cells (A375 human melanoma cells, A549 human lung cancer cells, MDA-MB-231 breast carcinoma cells and B164A5 murine melanoma cells) and healthy cells (HaCaT human keratinocytes) was examined in vitro by using a scratch assay technique. A number of $2 \times 10^{5}$ cells/well was cultivated in 12-well plates for $24 \mathrm{~h}$ prior to the experiment. A sterile pipette tip was used in order to draw scratches in well-defined zones of the cells monolayer (confluence of $80-90 \%$ ). Cells that detached as a result of the procedure were removed by washing with PBS before stimulation. The cells were stimulated with the three test compounds: TZ53, TZ55 and TZ3a following solubilization in DMSO $\left(c_{1}=10 \mu \mathrm{M}\right.$ and $\left.c_{2}=50 \mu \mathrm{M}\right)$. Images of the cells in culture were acquired at the starting point of the experiment, and after 3 and 24 h using an Optika Microscopes Optikam Pro Cool 5 and Optika View software.
Statistical analysis. Measurements were carried out in triplicate for each sample and the results are presented as the means \pm standard error. One-way ANOVA followed by Bonferroni's post-tests were used to determine the statistical difference between the experimental and control groups. A value of $\mathrm{P}<0.05$ was considered to indicate a statistically significant difference.

\section{Results and Discussion}

Molecular docking. The selection of the 5-mercapto-1,2,4-triazole moiety for the building of the compound library was based on previous studies that reported excellent antibacterial and antitumor properties of structurally similar compounds. Nadeem et al (24) reported the synthesis of 4,5-disubstituted-1,2,4-triazoles-3-thiols that proved active as antioxidants and exhibited antibacterial activity against Gram-positive cocci, as well as significant cytotoxic activity (24). In addition, in another study, 1,2,4-triazole-3-thione derivatives bearing pyrazole moieties were synthesized and tested against two human cancer cell lines, MCF7 (breast carcinoma) and HeLa (cervix carcinoma) cells using doxorubicin as a reference drug (25); all compounds revealed stronger cytotoxic activity than doxorubicin accompanied by moderate antibacterial activity.

Docking-based virtual screening (DBVS) aims to compute the interactions between a potential ligand and the binding site residues of a given protein-target. The binding affinity towards the target is predicted using a scoring function (26). Virtual screening methods, such as DBVS are extensively used in drug discovery to enhance cost-efficiency (27). Structure-based methods can be extensively applied due to numerous 3D crystallographic structures of key cancer targets. The docking process in the current study used the following protein structures: PI3K $\alpha$, AKT1 and mTOR.

$\mathrm{PI} 3 \mathrm{~K}$ is the enzyme that catalyzes the formation of phosphatidylinositol 3,4,5-trisphosphate (PIP3) from phosphatidylinositol 
4,5-bisphosphate (PIP2) (28). PIP3 is responsible for the activation of the enzyme, AKT, a serine/threonine-specific protein kinase which phosphorylates downstream effectors within cell survival, proliferation and metabolic pathways (29-31). One of these effectors is mTOR, a serine/threonine protein kinase from the phosphatidylinositol 3-kinase-related kinases (PIKK) family which modulates protein synthesis via the regulation of the phosphorylation state of translational proteins (Fig. 4), such as p70 ribosomal S6 kinase (P70S6K) and eukaryotic translation initiation factor 4E-binding protein 1 (4E-BP1) (32).

$\mathrm{PI} 3 \mathrm{~K}$ protein has been recognized as a major signaling molecule involved in various cellular mechanisms, such as cell proliferation and survival, as well as angiogenesis; therefore, the abnormal signaling of the PI3K pathway has beeen reported in almost $50 \%$ of human cancers (33). Mutations of the catalytic subunit PI3KCA of PI3K protein occur in many types of cancer, including colorectal cancer (34); in some cases, PI3K mutations are associated with a poor clinical outcome and prognosis.

Docked molecules were scored by the software's scoring function (Chemgauss4). From all sets of 3D protein structures corresponding to a target, the protein structure with the highest number of docked molecules was selected for further analysis. As the docking program has a ligand-based scoring function, selecting the structure with the highest number of docked compounds means that the respective protein binding site (or binding site conformation) is the most adequate for later receptor-target binding analysis. As such the following protein structures were selected for further analysis: PI3K $\alpha$-PDB ID: 4L2Y, AKT1-PDB ID: 3CQU and mTOR-PDB ID: 4DRH. In each case, the first 50 molecules ranked by the docking score were analyzed, taking into account the molecular interactions with binding site residues and the topological similarity with each cocrystalized ligand of the protein. For mTOR, compounds were docked in the binding site of rapamycin; given the fact that rapamycin is a very large molecule compared to the structures from the compound library used for docking, high scores were obtained for some of the structures. Nevertheless we concluded that the molecular sizes of the triazole derivatives were too small to accommodate well in the active binding site of the mTOR protein. In the case of PI3K protein, three small molecules TZ53, TZ55 and TZ3a, revealed good co-planarity with the co-crystallized ligand of $4 \mathrm{~L} 2 \mathrm{Y}$ and significant favorable interactions within the binding site. Similarly to the co-crystallized ligand, compounds formed hydrogen bonds (H-Bond) with the Asp810 and Tyr836 residues (Fig. 5).

Chemistry. As a result of docking analysis, compounds TZ53, TZ55 and TZ3a were synthesized and further tested for their toxicity and anticancer activity. Physicochemical analysis confirmed the structure of the three triazole derivatives:

1H-3-(4-ethoxyphenyl)-5-mercapto-1,2,4-triazole (3a) (TZ53). White powder; m.p.=225-227 ${ }^{\circ} \mathrm{C}$ IR [KBr] (cm-1): 3093, 3022, 2996, 2979, 2938, 2916, 1615, 1596, 1570, 1522, 1457, $1394,1300,1259,1229,1181,1118,1045,974,838,823,731$, 694, 549. 1H-NMR, 400.13 MHz, $\delta$ (ppm), DMSO-d6: 13.56 (s, br, H1, H6), 7.83 (d, J=8.4 Hz, 2H, H2', H6'), 7.04 (d, J=8.4 $\left.\mathrm{Hz}, 2 \mathrm{H}, \mathrm{H} 3^{\prime}, \mathrm{H} 5^{\prime}\right), 4.08$ (q, J=6.9 Hz, 2H, H8'), 1.33 (t, J=7.0 Hz, 3H, H9'). 13C-NMR, 100.6 MHz, $\delta$ (ppm), DMSO-d6: 166.6
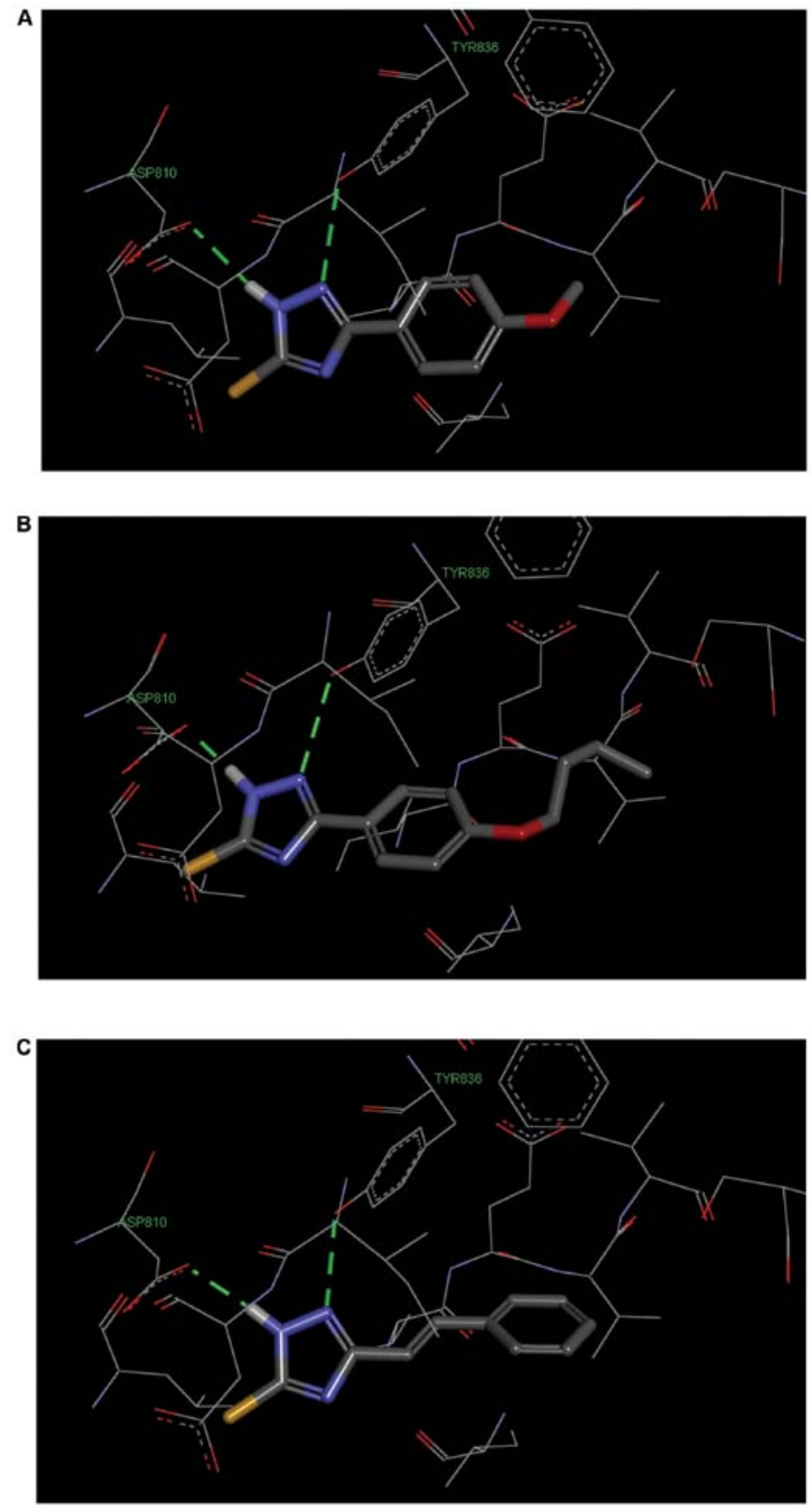

Figure 5. Compounds (A) TZ53, (B) TZ55, and (C) TZ3a, in the binding site of PI3K $\alpha$ (PDD ID: 4L2Y); H-Bond (green dotted lines) formed with Asp810 and Tyr836 residues; other types of interactions and amino acid labeling were omitted for image clarity.

(C5), 160.4 (C4'), 150.2 (C3), 127.4 (C2', C6'), 117.7 (C1'), 115.0 (C3', C5'), $63.4\left(\mathrm{C}^{\prime}\right), 14.6\left(\mathrm{C}^{\prime}\right)$. Elemental analysis, calculated for C10H11N3OS: C, 54.28; H, 5.01; N, 18.99; found: C, 54.12; $\mathrm{H}, 5.43$; N, 18.58. LC-MS Rt=0.431 $\mathrm{min}, m / z=222.0\left[\mathrm{M}+\mathrm{H}^{+}\right]^{+}$, $m / z=244.0\left[\mathrm{M}+\mathrm{Na}^{+}\right]^{+}$.

1H-3-(4-n-butoxyphenyl)-5-mercapto-1,2,4-triazoles (3b) (TZ55). White powder, m.p.=240-250 ${ }^{\circ} \mathrm{C}$ TLC: $($ Hexane:EA=1:1) $\mathrm{Rf}=0,64 \mathrm{IR}$ [KBr] (cm-1): 3065, 3026, 3000, 2957, 2936, 2909, 2871, 1616, 1568, 1522, 1484, 1456, 1295, 1252, 1228, 1189, 1070, 1025, 1008, 967, 831, 784, 735, 700, 553, 524. 1H-NMR, $400.13 \mathrm{MHz}, \delta$ (ppm), DMSO-d6: 13.7, 13.6 (H1, H6), 7.83 (d, $\left.\mathrm{J}=8.4 \mathrm{~Hz}, 2 \mathrm{H}, \mathrm{H} 2^{\prime}, 6^{\prime}\right), 7.04$ (d, J=8.8 Hz, 2H, H3',5'), 4.01 (t, $\left.\mathrm{J}=6.4 \mathrm{~Hz}, 2 \mathrm{H}, \mathrm{H} 8^{\prime}\right), 1.69$ (m, J=6.9 Hz, 2H, H9'), 1.42 (m, J=7.3 Hz, 2H, H10'), 0.92 (t, J=7.4 Hz, 3H, H11'). 13C-NMR, 100.6 
Table I. Antimicrobial activity of compounds TZ53, TZ55, TZ3a using the disk-diffusion method. ${ }^{\mathrm{a}}$

\begin{tabular}{lccccc}
\hline $\begin{array}{l}\text { Test } \\
\text { compound }\end{array}$ & $\begin{array}{c}\text { Concentration } \\
(\mu \mathrm{g} / \mathrm{ml})\end{array}$ & $\begin{array}{c}\text { Streptococcus } \\
\text { pyogenes } \\
\text { ATCC 19615 }\end{array}$ & $\begin{array}{c}\text { Pseudomonas } \\
\text { aeruginosa } \\
\text { ATCC 27853 }\end{array}$ & $\begin{array}{c}\text { Staphylococcus } \\
\text { aureus } \\
\text { ATCC 25923 }\end{array}$ & $\begin{array}{c}\text { Salmonella } \\
\text { typhimurium } \\
\text { ATCC 14028 }\end{array}$ \\
\hline TZ53 & 10 & $7 \mathrm{~mm}$ & $7 \mathrm{~mm}$ & $7 \mathrm{~mm}$ & $7 \mathrm{~mm}$ \\
& 25 & $7 \mathrm{~mm}$ & $7 \mathrm{~mm}$ & $7 \mathrm{~mm}$ & $7 \mathrm{~mm}$ \\
& 50 & $7 \mathrm{~mm}$ & $7 \mathrm{~mm}$ & $7 \mathrm{~mm}$ & $7 \mathrm{~mm}$ \\
& 100 & $7 \mathrm{~mm}$ & $7 \mathrm{~mm}$ & $7 \mathrm{~mm}$ & $7 \mathrm{~mm}$ \\
TZ55 & 10 & $7 \mathrm{~mm}$ & $7 \mathrm{~mm}$ & $7 \mathrm{~mm}$ & $7 \mathrm{~mm}$ \\
& 25 & $7 \mathrm{~mm}$ & $7 \mathrm{~mm}$ & $7 \mathrm{~mm}$ & $7 \mathrm{~mm}$ \\
& 50 & $7 \mathrm{~mm}$ & $7 \mathrm{~mm}$ & $7 \mathrm{~mm}$ & $7 \mathrm{~mm}$ \\
TZ3a & 100 & $7 \mathrm{~mm}$ & $7 \mathrm{~mm}$ & $7 \mathrm{~mm}$ & $7 \mathrm{~mm}$ \\
& 10 & $7 \mathrm{~mm}$ & $7 \mathrm{~mm}$ & $7 \mathrm{~mm}$ & $7 \mathrm{~mm}$ \\
& 25 & $7 \mathrm{~mm}$ & $7 \mathrm{~mm}$ & $7 \mathrm{~mm}$ & $7 \mathrm{~mm}$ \\
& 50 & $7 \mathrm{~mm}$ & $7 \mathrm{~mm}$ & $7 \mathrm{~mm}$ & $7 \mathrm{~mm}$ \\
\end{tabular}

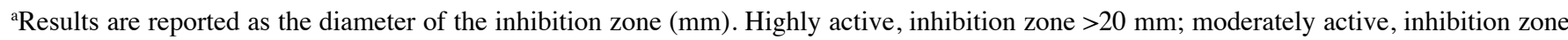
6-19 $\mathrm{mm}$; inactive, inhibition zone $<6 \mathrm{~mm}$.

MHz, $\delta(\mathrm{ppm})$, DMSO-d6: 166.6 (C5), 160.5 (C4'), 150.2 (C3), 127.4 (C2', C6'), 117.7 (C1'), 115.0 (C3', C5'), 67.5 (C8'), 30.6 (C9'), 18.8 (C10'), 13.7 (C11'). Elemental analysis, calculated for C12H15N3OS: C, 57.81; H, 6.06; N, 16.85; found: C, 58.01; H, 6.13; N, 16.37. LC-MS Rt $=0.426 \mathrm{~min}, m / z=272.1\left[\mathrm{M}+\mathrm{Na}^{+}\right]^{+}$.

1H-3-styryl-5-mercapto-1,2,4-triazoles (3c) (TZ3a). White powder,m.p. $=250-255^{\circ} \mathrm{C}\left(\mathrm{H}_{2} \mathrm{O}\right)$; TLC: $($ Hexan:EA=1:1) $\mathrm{Rf}=0,44$ IR [KBr] (cm-1):3455, 3387, 3095, 3025, 2962, 2905, 2849, 1651, 1565, 1507, 1469, 1448, 1309, 1219, 1011, 958, 857, 758, 730, 683, 517, 499. 1H-NMR, 400.13 MHz, $\delta$ (ppm), DMSO-d6: 13.59 (s, br, H1, H6), 7.59 (d, J=7.2 Hz, 2H, H4', H8'), 7.47 (d, J=16.8 Hz, 1H, H2'), 7.43-7.34 (3H, H5', H6', H7'), 6.96 (d, J=16.8 Hz, 1H, H1'). 13C-NMR, 100.6 MHz, $\delta$ (ppm), DMSO-d6: 166.7 (C5), 150.1 (C3), 135.4 (C2'), 135.1 (C3'), 129.4 (C6'), 129.0 (C5', C7'), 127.2 (C4', C8'), 112.5 (C1'). Elemental analysis, calculated for C10H9N3S: C, 59.09; H, 4.46; N, 20.67; found: C, 59.07; H, 4.82; N, 20.41. LC-MS Rt $=0.433 \mathrm{~min}, m / z=226.0\left[\mathrm{M}+\mathrm{Na}^{+}\right]^{+}$.

Antibacterial activity. The three compounds, TZ53, TZ55, TZ3a, were tested as antibacterial agents by the disk-diffusion method; the results are displayed in Table I.

The antimicrobial in vitro testing was conducted on four Gram-positive (Streptococcus pyogenes, Staphylococcus aureus) and Gram-negative (Pseudomonas aeruginosa, Proteus vulgaris) bacterial strains and Salmonella typhimurium. The triazole derivatives revealed a similar moderate antifungal and antibacterial activity with no visible variations between structures. Gupta and Jain (17) synthesized a set of Shiff bases, also based on the 5-mercapto-1,2,4-triazole scaffold, showing good antimicrobial activity; the moderate antimicrobial activity of our three synthesized compounds can be explained by comparison, taking into account the main structural similarities between the two sets of compounds: i) The main scaffold represented by the 5-mercapto-1,2,4-triazole moiety; ii) the substituted phenyl radical in the fifth position; and iii) a non-substituted thiol group in the third position. Nevertheless there are two main structural differences that consist in the absence of a radical in the fourth position (substituted bezylideneamino radical) and of halogen substitution of the phenyl radical from the fifth position (17), differences that may justify the weaker antibacterial activity of our triazole compounds.

Antiproliferative activity. The antiproliferative activity of the three triazole derivatives, TZ53, TZ55, TZ3a was tested on several tumor cell lines: A375 (human melanoma cells), B164A5 (murine melanoma cells), MDA-MB-231 (breast carcinoma cells) and A549 (lung carcinoma cells), as well as on one healthy cell line, $\mathrm{HaCaT}$ keratinocytes by means of alamarBlue assay. The results are displayed in Fig. 6. The alamarBlue assay is a simple test designed to quantitatively assess the number of viable cells; it incorporates a cell growth indicator (alamarBlue) that reacts to the cell metabolic activity by fluorescence and color change. More specifically, as a result of cell growth, the non-fluorescent oxidized blue form of the redox indicator turns into the fluorescent reduced red form and the result is spectrophotometrically evaluated (23). The graphical representation of the alamarBlue assay results depicted in Fig. 6 shows a moderate antiproliferative activity of the three compounds against the tumor cell lines used in this study. The antiproliferative activity against the A375 and B164A5 (melanoma cell lines, human and murine, respectively) was relatively poor for all compounds. A stronger activity was noted against the lung cancer cell line, A549, exerted in a dose-dependent manner. NVP-BEZ235 is a PI3K-mTOR dual inhibitor researched for its antiproliferative activity in various types of cancer $(35,36)$. Our result is consistent with that of thye study by Gong et al (36), that assessed the antiproliferative activity of multiple kinase inhibitors on various lung cancer cell lines and revealed that NVP-BEZ235 inhibited the proliferation of the A549 cell line. Therefore, we can presume that PI3K inhibition may be 


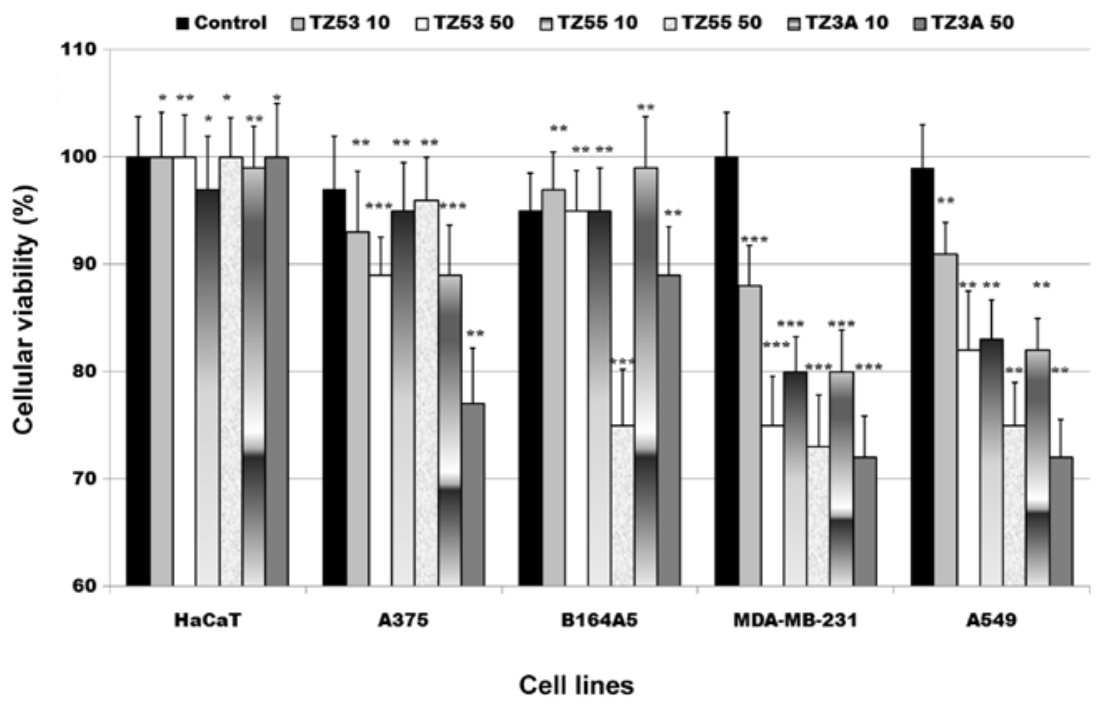

Figure 6. Cellular viability following the stimulation of normal (HaCaT keratinocytes) and cancer (A375, B164A5, MDA-MB-231, A549) cell lines with the three triazole derivatives TZ53, TZ55, TZ3a at concentrations of 10 and $50 \mu \mathrm{M} .{ }^{*} \mathrm{P}<0.05,{ }^{* *} \mathrm{P}<0.01$ and ${ }^{* * * *} \mathrm{P}<0.001$ vs. control.

accountable for the reported antiproliferative activity of our compounds against A549 cancer cells.

The highest antiproliferative activity was recorded against the breast cancer cell line, MDA-MB-231, an activity that can be corroborated with the results of the molecular docking analyses, which indicated the fitting of our triazole derivatives in the active binding site of PI3K protein. MDA-MB-231 is a human triple-negative breast cancer cell line characterized by the absence of estrogen and progesterone receptors and also lacking HER2 (receptor tyrosine-protein kinase erbB-2) amplification (37); it exhibits a high recurrence rate and poor prognosis. Thus far, there are only a few studies regarding the discovery of therapeutic targets in the treatment of triplenegative breast cancer. In 2014, Jia et al (38) reported that curcumin was cytotoxic to the MDA-MB-231 cell line, while another breast cancer cell line (MCF7) proved to be resistant; the antiproliferative activity of curcumin on MDA-MB-231 cells was linked to its inhibitory activity on the PI3K/Akt pathway and, moreover, the association of curcumin with a PI3K inhibitor, wortmannin, further increased MDA-MB-231 sensitivity (38). Another study reported the assessment of the cytotoxic activity of a selective PI3K inhibitor, GDC-0941 (39); the MDA-MB-231 cancer cell line became sensitive to this inhibitor after the siRNA-mediated silencing of the $O$-linked $N$-acetylglucosamine (GlcNAc) transferase (OGT) gene, without showing alterations of phosphorylated AKT levels. The combined treatment of the MDA-MB-231 cell line with metformin and carboplatin resulted in a synergistic inhibition of the AKT/mTOR pathway, thus leading to decreased cell cycle and cell proliferation (40). A highly relevant study carried out by Liu et al (41) in 2011 may provide an explanation regarding the major role the triazole ring plays in the selective targeting of PI3K protein. According to their study, the selective inhibition of $\mathrm{PI} 3 \mathrm{~K}$ protein is strongly required due to the high toxicity associated with mTOR protein simultaneous inhibition which disrupts cell metabolism; the authors reported the synthesis of an excellent PI3K selective inhibitor containing the triazole ring. This compound replaces the water molecule that forms a bridge $\mathrm{H}-\mathrm{Bond}$, in the ATP binding site of the PI3K $\alpha$ protein, between Asp810 and Tyr836; the nitrogen in position 1 acts as an $\mathrm{H}$-bond acceptor thus interacting with Tyr836, while nitrogen in position 2 of the triazole ring serves as an H-bond donor thus interacting with Asp810. The simultaneous presence of these interactions is essential for a strong inhibition of the PI3K $\alpha$ protein (41); our molecular docking studies clearly revealed these two interactions (Fig. 5), thus reliably predicting the biological results reported herein. Taking into account all these experimental results, we can state that the inhibition of MDA-MB-231 cell line is directly linked to the inhibition of $\mathrm{PI} 3 \mathrm{~K}$ protein as indicated by molecular docking. It is presumable that the triazole moiety plays an important role in the inhibition mechanism through its favorable accommodation within the active binding site of PI3K protein; since no significant differences were reported between the three compounds in terms of antiproliferative activity, the side chain does not seem to influence the antiproliferative activity. An important aspect of the in vitro testing is the toxicity assessment against normal HaCaT cell line; the lack of cytotoxic activity indicates low toxicity and selective antitumor activity.

Scratch assay. In light of the fact that concentrations of 10 and $50 \mu \mathrm{M}$ of tested compounds induced a relatively moderate activity against the viability of the four cancer cell lines, we assumed that these concentrations might inflict an inhibitory effect on tumor cells migration and proliferation. Therefore, the two concentrations of the three test compounds, 10 and $50 \mu \mathrm{M}$, respectively, were used for the scratch assay method which assesses cell migration and proliferation as a result of stimulation.

The scratch assay results are consistent with the antiproliferative results generated by the alamarBlue assay (data not shown); the highest antimigratory activity was reported for MDA-MB-231 cell line in both applied concentrations with no direct correlation between concentration and biologic effect. Similar results were recorded for A549 cell line where the inhibition of migration was seen only for the higher concentration. As noticed during the alamarBlue assay, A375 cell line 
exhibited the lowest sensitivity towards all test compounds. In terms of toxicological potential evaluated on HaCaT cells, all three compounds exhibited no antimigratory effects.

In conclusion, in the present study, we described the design and synthesis of three triazole derivatives with antibacterial and antiproliferative activity. The three evaluated structures emerged as a result of molecular docking which indicated a highly favorable accommodation within the active binding site of PI3K protein, thus acting as PI3K inhibitors and interfering with the PI3K/AKT pathway, a signaling cascade present in numerous types of cancer. The three compounds acted as antitumor agents against triple negative breast cancer (MDA-MB-231 cell line) and exhibited low toxicity and good selectivity thus offering promising perspectives in anticancer therapy.

\section{Acknowledgements}

The authors are grateful to OpenEye Scientific Software Inc. for providing academic license of their OEDocking software. The authors wish to thank Dr Florin Borcan for his assistance with the statistical analysis of thye experimental data. The work of Sorin Avram was supported by Project 1.2 of the Institute of Chemistry Timişoara of the Romanian Academy. This study was financially supported by a grant from the Romanian National Authority for Scientific Research and Innovation, CNCS - UEFISCDI, project number: PN-IIRU-TE-2014-4-2842.

\section{References}

1. Chinthala Y, Thakur S, Tirunagari S, Chinde S, Domatti AK, Arigari NK, K V N S S, Alam S, Jonnala KK, Khan F, et al: Synthesis, docking and ADMET studies of novel chalcone triazoles for anti-cancer and anti-diabetic activity. Eur J Med Chem 93: 564-573, 2015.

2. Palumbo MO, Kavan P, Miller WH Jr, Panasci L, Assouline S, Johnson N, Cohen V, Patenaude F, Pollak M, Jagoe RT, et al: Systemic cancer therapy: achievements and challenges that lie ahead. Front Pharmacol 4: 57, 2013.

3. Zugazagoitia J, Guedes C, Ponce S, Ferrer I, Molina-Pinelo S and Paz-Ares L: Current Challenges in Cancer Treatment. Clin Ther 38: 1551-1566, 2016.

4. Wu P, Nielsen TE and Clausen MH: FDA-approved smallmolecule kinase inhibitors. Trends Pharmacol Sci 36: 422-439, 2015.

5. Han F, Lin S, Liu P, Tao J, Yi C and $\mathrm{Xu} \mathrm{H}$ : Synthesis and structure-activity relationships of PI3K/mTOR dual inhibitors from a series of 2-amino-4-methylpyrido[2,3-d]pyrimidine derivatives. Bioorg Med Chem Lett 24: 4538-4541, 2014.

6. Zhao HF, Wang J and Tony To SS: The phosphatidylinositol 3-kinase/Akt and c-Jun N-terminal kinase signaling in cancer: Alliance or contradiction? (Review). Int J Oncol 47: 429-436, 2015.

7. Hollande F, Pannequin $\mathrm{J}$ and Joubert D: The long road to colorectal cancer therapy: Searching for the right signals. Drug Resist Updat 13: 44-56, 2010.

8. Toren P and Zoubeidi A: Targeting the PI3K/Akt pathway in prostate cancer: Challenges and opportunities (Review). Int J Oncol 45: 1793-1801, 2014

9. Sahu JK, Ganguly S and Kaushik A: Triazoles: A valuable insight into recent developments and biological activities. Chin J Nat Med 11: 456-465, 2013

10. Olah M, Rad R, Ostopovici L, Bora A, Hadaruga N, Hadaruga D, Moldovan R, Fulias A, Mractc M and Oprea TI: WOMBAT and WOMBAT-PK: bioactivity databases for lead and drug discovery. In: Chemical biology: from small molecules to systems biology and drug design. Schreiber SL, Kapoor TM and Wess G (eds) Vol 1-3. Wiley-VCH Verlag GmbH, Weinheim, pp760-786, 2008.
11. Li X, Li XQ, Liu HM, Zhou XZ and Shao ZH: Synthesis and evaluation of antitumor activities of novel chiral 1,2,4-triazole Schiff bases bearing $\gamma$-butenolide moiety. Org Med Chem Lett 2: 26, 2012.

12. Chowrasia D, Karthikeyan C, Choure L, Sahabjada S, Gupta M, Arshad Md and Trivedi P: Synthesis, characterization and anti cancer activity of some fluorinated 3,6-diaryl-[1,2,4] triazolo[3,4-b][1,3,4]thiadiazoles. Arab J Chem: 6-10, 2013.

13. Chand P, Chesney JA, Clem BF, Tapolsky GH, Telang S and Trent JO: Small-Molecule Choline Kinase Inhibitors As Anti-Cancer Therapeutics. Patent: US 2011/0257211 A1.

14. Hou YP, Sun J, Pang ZH, Lv PC, Li DD, Yan L, Zhang HJ, Zheng EX, Zhao J and Zhu HL: Synthesis and antitumor activity of 1,2,4-triazoles having 1,4-benzodioxan fragment as a novel class of potent methionine aminopeptidase type II inhibitors. Bioorg Med Chem 19: 5948-5954, 2011.

15. Georgiyants V, Perekhoda L, Saidov N and Kadamov I: Docking studies and biological evaluation of anti-cancer activity of new 1,2,4-triazole (4h) derivatives. Scr Sci Pharm 1: 46-53, 2014.

16. Holla BS, Sarojini BK, Rao BS, Akberali PM, Kumari NS and Shetty V: Synthesis of some halogen-containing 1,2,4-triazolo-1,3,4-thiadiazines and their antibacterial and anticancer screening studies - part I. Farmaco 56: 565-570, 2001.

17. Gupta D and Jain DK: Synthesis, antifungal and antibacterial activity of novel 1,2,4-triazole derivatives. J Adv Pharm Technol Res 6: 141-146, 2015.

18. Hawkins PCD, Skillman AG, Warren GL, Ellingson BA and Stahl MT: Conformer generation with OMEGA: Algorithm and validation using high quality structures from the Protein Databank and Cambridge Structural Database. J Chem Inf Model 50: 572-584, 2010.

19. McGann M: FRED and HYBRID docking performance on standardized datasets. J Comput Aided Mol Des 26: 897-906, 2012.

20. Berman HM, Westbrook J, Feng Z, Gilliland G, Bhat TN, Weissig H, Shindyalov IN and Bourne PE: The protein data bank. Nucleic Acids Res 28: 235-242, 2000.

21. Gurusaran M, Shankar M, Nagarajan R, Helliwell JR and Sekar K: Do we see what we should see? Describing non-covalent interactions in protein structures including precision. IUCrJ 1: 74-81, 2013.

22. Bercean VN, Badea V, Sisu E, Bindila L and Csunderlik C: A simplified method of obtaining 3-aryl-5-mercapto-1,2,4-triazoles. Rev Chim 54: 368-369, 2003.

23. Soica C, Oprean C, Borcan F, Danciu C, Trandafirescu C, Coricovac D, Crăiniceanu Z, Dehelean CA and Munteanu M: The synergistic biologic activity of oleanolic and ursolic acids in complex with hydroxypropyl- $\gamma$-cyclodextrin. Molecules 19: 4924-4940, 2014.

24. Nadeem H, Mohsin M, Afzaal H, Riaz S, Zahid A and Muhammad SA: Synthesis and in Vitro Biological Activities of 4,5-Disubstituted 1,2,4-Triazole-3-Thiols. Adv Microbiol 3: 366-375, 2013.

25. El-Sayed WA, Flefel EM and Morsy EMH: Anticancer and antimicrobial activities of some synthesized pyrazole and triazole derivatives. Pharmachem 4: 23-32, 2012.

26. Cheng T, Li Q, Zhou Z, Wang Y and Bryant SH: Structure-based virtual screening for drug discovery: A problem-centric review. AAPS J 14: 133-141, 2012.

27. Ferreira LG, dos Santos RN, Oliva G and Andricopulo AD: Molecular Docking and Structure-Based Drug Design Strategies. Molecules 20: 13384-13421, 2015.

28. Oda A, Saijo K, Ishioka C, Narita K, Katoh T, Watanabe Y, Fukuyoshi $\mathrm{S}$ and Takahashi O: Predicting the structures of complexes between phosphoinositide 3-kinase (PI3K) and romidepsin-related compounds for the drug design of $\mathrm{PI} 3 \mathrm{~K} / \mathrm{histone}$ deacetylase dual inhibitors using computational docking and the ligand-based drug design approach. J Mol Graph Model 54: 46-53, 2014.

29. Saini KS, Loi S, de Azambuja E, Metzger-Filho O, Saini ML, Ignatiadis M, Dancey JE and Piccart-Gebhart MJ: Targeting the PI3K/AKT/mTOR and Raf/MEK/ERK pathways in the treatment of breast cancer. Cancer Treat Rev 39: 935-946, 2013.

30. Nitulescu GM, Margina D, Juzenas P, Peng Q, Olaru OT, Saloustros E, Fenga C, Spandidos DA, Libra M and Tsatsakis AM: Akt inhibitors in cancer treatment: The long journey from drug discovery to clinical use (Review). Int $\mathbf{J}$ Oncol 48: 869-885, 2016. 
31. Häggblad Sahlberg S, Mortensen AC, Haglöf J, Engskog MK, Arvidsson T, Pettersson C, Glimelius B, Stenerlöw B and Nestor M: Different functions of AKT1 and AKT2 in molecular pathways, cell migration and metabolism in colon cancer cells. Int J Oncol 50: 5-14, 2017.

32. Vignot S, Faivre S, Aguirre D and Raymond E: mTOR-targeted therapy of cancer with rapamycin derivatives. Ann Oncol 16: 525-537, 2005

33. Fyffe $\mathrm{C}$ and Falasca M: 3-Phosphoinositide-dependent protein kinase-1 as an emerging target in the management of breast cancer. Cancer Manag Res 5: 271-280, 2013.

34. Cathomas G: PIK3CA in Colorectal Cancer. Front Oncol 4: 35 , 2014

35. Moon G, Lee SE, Oh MM, Lee SC, Jeong SJ, Hong SK, Yoon CY, Byun SS, Park HS and Cheon J: NVP-BEZ235, a dual $\mathrm{PI} 3 \mathrm{~K} / \mathrm{mTOR}$ inhibitor synergistically potentiates the antitumor effects of cisplatin in bladder cancer cells. Int J Oncol 45: $1027-1035,2014$

36. Gong HC, Wang S, Mayer G, Chen G, Leesman G, Singh S and Beer DG: Signatures of drug sensitivity in nonsmall cell lung cancer. Int J Proteomics 2011: 215496, 2011.
37. Yi YW, Hong W, Kang HJ, Kim HJ, Zhao W, Wang A, Seong YS and Bae I: Inhibition of the PI3K/AKT pathway potentiates cytotoxicity of EGFR kinase inhibitors in triple-negative breast cancer cells. J Cell Mol Med 17: 648-656, 2013.

38. Jia T, Zhang L, Duan Y, Zhang M, Wang G, Zhang J and Zhao Z: The differential susceptibilities of MCF-7 and MDA-MB-231 cells to the cytotoxic effects of curcumin are associated with the PI3K/Akt-SKP2-Cip/Kips pathway. Cancer Cell Int 14: 126, 2014.

39. Kwei KA, Baker JB and Pelham RJ: Modulators of sensitivity and resistance to inhibition of $\mathrm{PI} 3 \mathrm{~K}$ identified in a pharmacogenomic screen of the NCI-60 human tumor cell line collection. PLoS One 7: e46518, 2012.

40. Liu H, Scholz C, Zang C, Schefe JH, Habbel P, Regierer AC, Schulz CO, Possinger K and Eucker J: Metformin and the mTOR inhibitor everolimus (RAD001) sensitize breast cancer cells to the cytotoxic effect of chemotherapeutic drugs in vitro. Anticancer Res 32: 1627-1637, 2012.

41. Liu KKC, Zhu J, Smith GL, Yin MJ, Bailey S, Chen JH, Hu Q, Huang Q, Li C, Li QJ, et al: Highly Selective and Potent Thiophenes as PI3K Inhibitors with Oral Antitumor Activity. ACS Med Chem Lett 2: 809-813, 2011. 